\title{
Rhythms of the Night: Spatiotemporal Inequalities in the Night-Time Economy
}

\author{
Tim Schwanen \\ Transport Studies Unit \\ School of Geography and the Environment \\ University of Oxford \\ South Parks Road, Oxford \\ OX1 3QY, England \\ tim.schwanen@ouce.ox.ac.uk \\ Irina van Aalst \\ Department of Human Geography and Planning \\ Faculty of Geosciences \\ Utrecht University \\ P.O. Box 80115 \\ 3508 TC Utrecht, The Netherlands \\ i.vanaalst@uu.nl \\ Jelle Brands \\ Department of Human Geography and Planning \\ Faculty of Geosciences \\ Utrecht University \\ P.O. Box 80115 \\ 3508 TC Utrecht, The Netherlands \\ j.brands@uu.nl \\ Tjerk Timan \\ Science, Technology, and Policy Studies (STəPS) \\ School of Management and Governance \\ University of Twente \\ P.O. Box 217 \\ 7500 AE Enschede, The Netherlands \\ t.timan@utwente.nl
}

Paper prepared for the special issue on "Critical Space-Time Geographies", guest edited by Tim Schwanen and Mei-Po Kwan for Environment and Planning A

Original submission: 2 September 2011

Final submission: 3 February 2012 


\title{
Rhythms of the Night: Spatiotemporal Inequalities in the Night-Time Economy
}

\begin{abstract}
This paper seeks to extend the literature on inequalities and exclusion in the night-time economy through a rhythmic analysis of visitor presence in public space in nightlife districts in the city-centres of the Dutch cities of Groningen, Utrecht and Rotterdam. We demonstrate substantial inequalities in visitor presence based on race/ethnicity and gender. In the cities considered racial/ethnic inequalities vary more in spatial terms and gender inequalities fluctuate more heavily over the course of the night. Overall, however, the findings support the argument that exclusion from the night-time economy needs to be understood in temporal-ecological terms. Multiple drivers or pacemakers of rhythmic inequalities rooted in race/ethnicity and gender are identified, including opening hours and revellers' collective habits. For advocates of greater diversity among night-time economy participants our analysis suggests that a more varied supply of nightlife premises or more surveillance and policing are no straightforward solutions: a strong orientation of premises on university students and urban professionals may promote gender-based inclusion but deters non-white revellers, and more police on the street may empower women to move through a nightlife district unaccompanied yet reduce the inclination to do so among racial/ethnic minorities.
\end{abstract}

Keywords:

Night-time economy; exclusion; rhythm; gender; ethnicity; Netherlands 


\section{Introduction}

It is by now well established that across the Western world the expansion of city-centre nightlife entertainment is a common governmental strategy for stimulating the local economy (Chatterton and Hollands, 2003; Roberts and Eldridge, 2009). Whilst the growth of bars, clubs, restaurants, and theatres has indeed drawn visitors and consumer spend into city-centres, the downsides of this expansion have also been foregrounded in the popular press and academia. These include moral panics about binge-drinking and alcohol-fuelled disorder and about the exclusion of certain social groups from the nighttime economy (Talbot, 2007; Measham and Hadfield, 2009). Common responses to such excesses have been legislative reform, such as the UK's Licensing Act 2003, and intensified surveillance and policing (Hadfield et al, 2009; Roberts and Eldridge, 2009). The success of such initiatives is, however, not always evident (cf Hadfield et al, 2009). In the Netherlands, for instance, the discriminatory practices of door staff at nightlife premises against youth from Moroccan, Turkish or Surinamese/Antillean descent - the country's largest racial/ethnic minority groups - caused considerable public indignation in the 2000s. Although door policy is now regulated more strongly, many revellers from Arabic descent still feel discriminated in the night-time economy (Boogaarts, 2008).

Exclusion, or inability to participate as consumers, in the night-time economy seems to occur at two levels: a strong overrepresentation of young people has been observed (Roberts and Turner, 2005; Thomas and Bromley, 2000) and within this youth dominance, inequalities rooted in class (Chatterton and Hollands, 2003; Bromley et al, 2003), race/ethnicity (Böse, 2005; Measham and Hadfield, 2009; Talbot, 2007) and to a lesser extent gender (Bromley et al, 2003; Sheard, 2011). Through in-depth interviews and ethnography scholars have identified many mechanisms through which the latter forms of exclusion operate. For Chatterton and Hollands (2003) the exclusion of lowerclass, non-white and non-mainstream revellers from UK city-centres reflects the spatial marginalisation of such nightlife spaces as traditional community pubs, ale houses and 
venues playing alternative music; both are a consequence of the branding and 'theming' of mainstream nightlife by corporate actors aiming to maximise profits by attracting relatively riskless cash-rich consumers, such as students and young urban professionals (see also Talbot [2007]; for critiques, see Latham [2003] and Jayne et al. [2006]).

Exclusion along racial/ethnic lines has also resulted from one or more of the following causes (Boogaarts, 2008; Böse, 2005; Measham and Hadfield, 2009): the licensing practices of local authorities; entry requirements and discrimination by clubs and door staff; drink and entry prices; clubs' marketing techniques and use of online registration and members-only strategies; and the programming of music in mainstream nightlife, the criminalisation of black music on the basis of racist stereotypes, and refusal of club owners to host black music nights. But the practices of other visitors, parents and youngsters themselves also matter. In contrast to their male counterparts, DutchTurkish young women are often not allowed to go out by their parents (Boogaarts, 2008). And Dutch-Turkish youngsters often defect from mainstream nightlife because of an experienced lack of belonging and safety (ibid.), whilst the culture of abstinence from alcohol tends to exclude many Muslim youth in the UK from the city-centre night-time economy (Valentine et al, 2010). Boogaarts (2008) also showed that there are many differentiations among Dutch-Turkish youth. She confirmed the more general observation (Chatterton and Roberts, 2003; Hadfield, 2008) that revellers continually distinguish themselves from and exclude their peers, whilst (re)creating their subcultural capital through nightlife practices.

Few studies to date have addressed gender-based forms of exclusion in the night-time economy but Sheard's (2011) research in Leeds suggests that female study participants refrain from visiting bars alone or walking home alone and that some of them avoid citycentres at night altogether. According to Thomas and Bromley (2000), discourses of fear of crime prohibit women more than men from going out in Swansea and Cardiff. 
Notwithstanding the considerable insight in the mechanisms of exclusion, less is clear about the extent of inequality and exclusion along lines of race/ethnicity and gender across space and time in night-time economies, and about if and how spatiotemporal inequalities among visitors co-evolve with such factors as the type of nightlife entertainment on offer, openings hours and surveillance and policing over the course of a single night and across days of the week. The relative neglect of the temporal dimensions of inequality and exclusion is somewhat surprising in light of the distinction between the evening, night and late-night economy that has been made (Bromley et al, 2003; Rowe and Bavinton, 2011). In this paper we employ the concept of rhythm to integrate the spatial and temporal dimensions of inequality and exclusion and to link these to other spatiotemporal dynamics, such as opening hours and the visible presence of surveillance and policing agents. More specifically, we offer a rhythmanalysis of racial/ethnic and gender inequalities among participants in the night-time economy, drawing on empirical data collected with mixed methods in the Dutch cities of Groningen, Utrecht and Rotterdam. The mixed-method approach notwithstanding, this paper foregrounds the quantitative dimensions of our analysis. As such it complements the more commonly used ethnographic and interview approaches and builds on geography's critical quantitative tradition (Sheppard, 2001; Kwan and Schwanen, 2009).

\section{The rhythms of urban nightlife}

\subsection{Rhythms}

At least since the introduction of time-geography to the Anglophone world (Hägerstrand, 1970) have geographers had a conceptual apparatus to think about rhythms (Crang, 2001). Nonetheless, Parkes and Thrift's $(1979,1980)$ chronogeography - directly inspired by time-geography - offered the first comprehensive treatment of rhythmicity in human geography, but has since been complemented with other approaches, including 
Adam's timescape framework (Adam, 2004), Lefebvrian rhythmanalysis (Lefebvre, 2004; Edensor and Holloway, 2008) and non-representational styles of analysis (Amin and Thrift, 2002; Jones, 2011). This paper draws primarily on chronogeographical and Lefebvrian rhythmanalysis.

For Lefebvre (2004:15) rhythms involve birth-growth-peak-decline-end cycles and recurrence. This recurrence does not amount simply to mechanistic reproduction of the same phenomenon but is a complex combination of such linearity with novelty: rhythms entail repetition with difference. Rhythms are also "interaction[s] between a place, a time and an expenditure of energy" (ibid.) and allows us to think about temporal ecologies (Jones, 2011). And they are multiple: rhythms can be corporeal (e.g. sleepwake cycles), 'natural' (e.g. daylight), institutionally inscribed (e.g. opening hours) and collective routines (e.g. the transient visitor presence in bars). Moreover, rhythms differ in frequency, intensity and regularity; they both interact harmoniously and clash with each other continuously; and they form polyrhythmic ensembles from which spatiotemporal consistencies and places emerge (Amin and Thrift, 2002; Parkes and Thrift, 1980). On this view, cities - or parts thereof - are constituted by intricate mixtures of rhythms and questions about the factors producing rhythmic conformity are central to understanding night-time economies and cities more generally.

The notion of entrainment, originally developed in chronobiology but also featuring prominently in Parkes and Thirft's $(1979,1980)$ chronogeography, aids our understanding of rhythmic conformity and place formation. Entrainment is the process of synchronisation whereby certain elements - Zeitgebern or pacemakers - impel others to take over or adjust to their rhythm. The stronger the entraining capacities of an element, the more its effects will ripple through a polyrhythmic ensemble as an accordion effect (ibid.) and the greater the rhythmic conformity that will ensue. Entrainment should not, however, be seen as a deterministic and top-down or hierarchical process emanating from a single core or a few centres. Different theoretical 
registers - Lefebvre's (2004) rhythmanalysis, chronobiology (Hastings et al, 2003), DeLanda's (2002) philosophy and Strogatz's (2003) mathematics of synchronisation hold that entrainment is open-ended, characterised by contestation and based on local self-organisation. Pacemakers, then, come in many shapes and forms. Strogatz (2003), for instance, holds that agents as diverse as atoms, people and planets have their own clocks whose timings adjust to each others. DeLanda (2002) nonetheless suggests as a rule of thumb that agents characterised by slower rates of change will be entraining other elements, at least in the short run. This view concurs with the observation that institutionally inscribed rhythms, such as opening hours of facilities and public transport timetables, are capable of entraining the rhythms of many practices and people in a given place (Parkes and Thrift, 1980).

\subsection{Pacemaking the night-time economy}

Previous research on the night-time economy provides valuable insight into its rhythmicity and the processes through which the rhythms of transient visitor populations are entrained. Roberts and Turner's (2005) descriptive study of Old Crompton Street in Soho, London indicates that a nightlife district is indeed a polyrhythmic ensemble in which pedestrian activity, traffic, noise levels, instances of anti-social behaviour and opening hours of facilities fluctuate and interact over a $24 \mathrm{~h}$ period. Their work suggests that the opening times and availability of different nightlife facilities - bars, clubs, pavement cafés, etcetera - act as pacemakers for the number of visitors that could be observed on the street. Other research (Bromley et al, 2003; Rowe and Bavinton, 2011) put forward a temporal differentiation in visitor profiles based on the availability and opening hours of different nightlife facilities. A distinction is proposed between an evening economy premised on visits to restaurants, cafés, theatres, concerts and cinemas by a relatively heterogeneous population in terms of age, class and gender; a night economy in which predominantly youth and more males than females tend to frequent bars and clubs; and a late-night economy organised around nightclubs and in 
which alcohol-fuelled crime and disorder are concentrated. Rowe and Bavinton (2011) suggest $11: 00 \mathrm{PM}$ and $2: 00 \mathrm{PM}$ as the approximate times of transition between the three periods.

The entraining capacities of the opening hours of nightlife facilities have also been discussed in studies into the effects of the UK Licensing Act 2003, through which the opening hours of bars and clubs can be extended more easily (Kirby and Hewitt, 2011; Roberts and Eldridge, 2009). The rationale behind this regulatory reform was that a dispersal of opening hours along the time axis would lower the density of people on the street, weaken the practice of drinking large quantities of alcohol before closing time, and so lower alcohol-fuelled disorder. Although extensions in licensing hours have generally been short, a small displacement of crime and disorder and drinking into the late night has been observed (ibid.).

Several studies (Roberts and Turner, 2005; Thomas and Bromley, 2000; Van Aalst and Schwanen, 2009) indicate that perceptions of crime, disorderliness and unsafety increase over the course of the night and are one of the factors that keep people from participating in the night-time economy in the later hours. To the best of our knowledge, however, it is unclear if and how such entrainment effects are mediated by the presence of police officers, door staff and other forms of surveillance. Exploratory interviews with night-time economy participants in several Dutch cities by two of us (Van Aalst and Schwanen, 2009) nonetheless suggest that the presence of police and other surveillance agents and their 'stage props' (Goffman, 1959) - clothing and equipment and particularly whether they are on a bike, on horseback, in a car or simply on foot - is not always evaluated positively. A strong visible presence of well-equipped surveillance agents may draw some people into the night-time economy yet trigger suspicion in and deter others. It goes without saying that it is not necessarily clear who/what entrains and who/what is entrained in the interacting rhythms of visitor presence, surveillance and policing and disorderliness. The rhythmic presence of police officers, for instance, 
may reflect the anticipation, on the basis of past experiences, of undesired events and risks involving certain (types of) visitors at particular times and places during the night. Entrainment in the night-time economy is often a process of co-evolution and reciprocity that defies the neat linearity of pas, presence and future.

At the same time, our exploratory research also suggested that the rhythmic participation of individual revellers in the night-time economy is shaped by collective routines - what others do - as well as the composition of transient visitor populations in terms gender, race/ethnicity and other axes of social differentiation. Some female interviews indicated to avoid public spaces and nightlife facilities dominated by younger men (Van Aalst and Schwanen, 2009; see also Sheard, 2011).

\subsection{Pace-making exclusion in urban nightlife}

Thinking in rhythms draws attention to short-term dynamics in and fluidity of inequality and exclusion in a city-centre's night-time economy. It foregrounds that differences along lines of race/ethnicity, gender and other identity markers in transient visitor populations result not only from relatively durable or 'structural' factors, such as the type and theming of nightlife premises on offer (Bromley et al, 2003; Chatterton and Hollands, 2003), the programming of music (Boogaarts, 2008; Böse, 2005) or cultures of abstinence (Valentine et al, 2010). Those differences also shift, shrivel and swell over the course of a single night or a week. Further, rhythmic patterns of inequality and exclusion may reflect that the pacemakers discussed in sub-section 2.2 operate more forcefully or in different ways for young men and women and/or for different racial/ethnic groups. Therefore, the empirical analysis below examines the rhythms of exclusion in terms of gender and race/ethnicity in the night-time economies of the Dutch cities of Groningen, Utrecht and Rotterdam. 
Following past research (Bromley et al, 2003; Roberts and Turner, 2005; Thomas and Bromley, 2000), we might expect young women to be particularly excluded in the latenight economy. Care should be taken, however, to avoid treating young women as a homogeneous category or to position them as simply fearful or victims of alcohol-fuelled disorder: the literature on fear of crime in public spaces has indicated that young women (and men) use a wide variety of tactics to negotiate such spaces (Koskela, 1997; Pain, 2000). Rather, the entrainment of women's participation in the night-time economy by such factors as disorderliness, collective routines and the composition of transient visitor populations in a certain time and place is open-ended and non-deterministic: some women may be deterred from participation but others may not be deterred.

Given the multifarious 'structural' mechanisms through which racial/ethnic minorities have been excluded from mainstream nightlife (Boogaarts, 2008; Böse, 2005; Measham and Hadfield, 2009; Talbot, 2007), we might expect rhythmic variations in the racial/ethnic diversity of night-time economy participation to be less pronounced than spatiotemporal differences along lines of gender. Still, inequality and exclusion in terms of race/ethnicity might be more severe in the night-time and especially the late-night economy. These are after all the periods when door staff are employed most widely and non-white youngsters might fear or perceive discriminatory door practices ( $c f$ Boogaarts, 2008) and when most alcohol is consumed, from which religious youngsters from Arabic descent may seek to dissociate themselves (cf Valentine et al, 2010).

\section{Data}

For the empirical analysis we utilise dedicated information from systematic observations on Thursday, Friday and Saturday nights in the city-centres of Groningen, Utrecht and Rotterdam. Those nights were chosen because they are the busiest and attract different crowds: Thursday is the typical students' night out, whilst Fridays and particularly 
Saturdays attract more school-going adolescents and (full-time employed) younger adults. In each city-centre Jelle and Tjerk conducted observations during five ten-minute intervals between \pm 10 : $00 \mathrm{PM}$ and \pm 5 :00AM on four different sites. In total information is available for ( 3 cities $\times 3$ nights $\times 4$ sites $\times 5$ rounds $=$ ) 180 ten-minute observation periods during nine nights in March-April 2010. The first round of observations of all four sites on a given night was completely around 23:30PM and coincides with what has been called the evening economy (see above). Rounds II and III tended to coincide with the night-time economy, and IV and $\mathrm{V}$ - the period from \pm 2 :30AM onwards - with the latenight economy.

A wealth of information was collected per observation interval. Independent from each other, Jelle en Tjerk registered the number of visitors they saw, segmented by race/ethnicity and gender and the size of the groups of individuals dwelling in or traversing public space at the observation site. They also recorded the number of and equipment used by police officers, private security (including door staff) and street wardens; instances of disorder; the weather; and the presence of distinct smells. Finally, they audio-recorded narrative accounts of events and the atmosphere during each interval. We relied on direct observation instead of filming and time-lapse photography (as in Roberts and Turner, 2005; Whyte, 1980), because we felt direct observation would allow for more precise identification of people's characteristics; had no access to cameras offering high-quality footage of scenes in poorly lit places or at a greater distance; and also wanted to collect olfactory and auditory information (following Lefebvre, 2004).

The data collection centred on public spaces in nightlife districts. In part this was a pragmatic choice: streets and squares lend themselves better to observational research than does the interior of nightlife premises. More importantly, the streets and squares considered are in principle available to anyone. If forms of inequality and exclusion exist here, questions can be raised about the nature of public spaces and local public policies 
regarding such spaces at night-time. Further, conclusions regarding who has visited bars and clubs can, up to a degree, be inferred from the collected information because the public spaces considered provide entry to nightlife premises.

The information on visitors, surveillance and policing, disorderliness, the weather and smells has been digitised and categorised, and the verbal accounts have been transcribed. Jelle and Tjerk's individual records of the number and composition of visitors during each observation interval have been compared and combined. Two estimates of visitor numbers by gender, race/ethnicity and group size per interval have been created - a low and a high variant. Sensitivity analysis has indicated that the low and high variants are highly correlated. However, we only report the high variant in this paper as Jelle and Tjerk felt they might not have been able to count all visitors during a few extremely busy observation intervals.

The collected information enables a mixed-method approach in which qualitative and quantitative information is combined. Such an approach has been pursed indeed, although the quantitative dimension of the analysis is foregrounded in the current paper. This is mainly because this paper is exploratory in nature: it seeks to provide a broadbrush picture of inequality and exclusion in night-time economies and to open up new research questions to be explored with other research methods. However, for the interpretation of the quantitative results we have relied extensively on analyses of Jelle and Tjerk's verbal accounts recorded during the observations, preliminary in-depth interviews with revellers in Utrecht and other Dutch cities, and further (qualitative) materials collected in the context of the research programme of which the observations were part. 


\section{Selection and description of study areas}

The observations have been conducted in the main nightlife districts of Groningen, Utrecht and Rotterdam, the Netherlands. These cities have been chosen because of differences in population composition, spatial structure of the nightlife district, and surveillance and policing practices. Groningen's nightlife entertainment has a regional function for the northeast of the Netherlands and caters to the city's large student population. Groningen is also known for a strong focus on technological innovation in regulating the night-time economy's excesses, evidenced in extensive experimentation with smart CCTV cameras equipped with sound sensors between 2006 and 2010. In spatial terms the nightlife district is strongly concentrated around its central square (Grote Markt) and the streets to the immediate southeast (Figure 1). Photographic impressions are included in the supplementary online material.

Rotterdam is also innovative in terms of regulating the night-time economy, but the focus is more on zero-tolerance policing than on technological innovation. Equally important, Rotterdam is a post-industrial city that has seen a large influx of racial/ethnic minorities in past decades. At present $37 \%$ of the population is of non-western primarily Turkish, Moroccan, Surinamese/Antillean - descent, against $22 \%$ in Utrecht and $10 \%$ in Groningen. ${ }^{1}$ Another difference with Groningen is that Rotterdam's nightlife district is more dispersed spatially. We consider the area from the Schouwburgplein to the Stadhuisplein, which houses a large concentration and diversity of nightlife entertainment facilities (Figure 2 and online material). Utrecht is in many ways our average city: its nightlife district is less concentrated than Groningen's but more than Rotterdam's, the city as a whole is less student-oriented than Groningen but more than Rotterdam, and its population is racially/ethnically more diverse than Groningen's but not so much as Rotterdam's (Figure 3 and online material).

\footnotetext{
${ }^{1}$ The percentages have been derived from information (in Dutch) on the websites of the municipalities of Groningen (www.os-groningen.nl), Utrecht (http://www.utrecht.nl/smartsite.dws?id=214) and Rotterdam (www.cos.rotterdam.nl), which were accessed in August 2011.
} 
<Figures 1-3 here>

For the observations four sites were selected in each nightlife district, based on preliminary observations in each city-centre. The sites are located in close vicinity of key nightlife premises in each city and allowed us to obtain reliable and robust visual impressions of the number and diversity of people present and events occurring in different parts of the cities' nightlife district.

The nightlife entertainment differs across and within the three city-centres. In Groningen much of the available entertainment is oriented towards students with a mix of pubs, snack bars and restaurants. Papengang (site IV), however, houses a Dutch-style coffee shop (sale and consumption of soft drugs) and a non-mainstream club. Utrecht's nightlife entertainment consists of a mix of restaurant, (small) pubs and clubs strongly oriented towards university students and young urban professionals. This is particularly the case on Thursdays when many clubs have students-only nights and for the Janskerkhof area (sites I and II). However, the north-west side of the Neude square (site III) is more diversified and houses a large club which plays mainly house and funk music and also targets non-students explicitly. In Rotterdam the spatial segmentation of nightlife entertainment is stronger than in the other cities. The Schouwburgplein area (site I) houses a theatre and casino in addition to pubs and restaurants, and thus many facilities associated with the evening economy. Kruiskade (sites II and III) and Stadhuisplein (site IV) are characterized more by late-night facilities targeting different crowds: the former houses a mix of heterogeneous mainstream and alternative venues (from R\&B clubs and lounge bars to an Irish pub and alternative club), whilst the latter accommodates a series of relatively uniform, themed bars and clubs with a strong focus on mainstream pop music. 


\section{Visitor rhythms}

\subsection{Indicators}

To obtain insight in the degree of inequality and exclusion along lines of race/ethnicity and gender, we will use six simple indices of visitor presence that can be calculated for each of the 180 observation rounds. We emphasise that there is no one-to-one relation between the (relative) absence from the night-time economy of people belonging to a given social category and their actual exclusion. Nonetheless, the degree of inequality in the presence of a given racial/ethnic or gender category does give robust indications of potential exclusion.

The total number of visitors observed per ten-minute interval will serve as a backdrop; it shows how many people are participating in the night-time economy across the night and days of the week. Racial/ethnic diversity is measured through an entropy index

defined as $-\Sigma_{j=1}^{l} \frac{x_{j} \ln x_{j}}{\ln J}$ with $x_{j}$ representing the percentage of visitors in category $j$. Six such categories are considered: white/Caucasian, black, Arabic, East-Asian, Latino, and other. A value of 1 indicates perfect balance or equal shares across all categories, 0 that all visitors belong to a single racial/ethnic category. The share of women in the total number of visitors per ten-minute interval measures gender balance and thus potential gender-based exclusion.

Our final three indicators measure the extent to which visitors are traversing public space unaccompanied or in a group of two or more people. Our preliminary research (Van Aalst and Schwanen, 2009) and the work of others (Roberts and Eldridge, 2009; Sheard, 2009; Thomas and Bromley, 2000) has suggested that both male and female night-economy participants mitigate fear of crime by traversing public space in groups rather than alone. There are of course reasons other than fear for traversing streets in 
the night-time economy in groups, including fun and a sense of belonging. Yet, our preliminary research makes us believe that visitors traversing public spaces in the nighttime economy unaccompanied feel confident and safe enough to do so. The share of unaccompanied visitors is therefore a fairly robust quantitative indicator of night-time economy participants' self-confidence, empowerment and inclusion. One of our indicators equals the share of unaccompanied persons in general and functions as a backdrop for the other two. The other two indicators measure the share of unaccompanied women in the total number of visitors per observation interval, and of unaccompanied non-white ${ }^{2}$ individuals in the total number of non-white visitors. Note that the last indicator has a different denominator; this reflects that the share of non-white visitors is both low in general - the average is only $22.3 \%$ across all observation rounds - and strongly unequal across Groningen (15.4\%), Utrecht (11.2\%) and Rotterdam (42.2\%).

\subsection{Rhythms of visitor presence}

The size of transient visitor populations differed notable across space and time. The sites in Groningen were on average about two and three times as busy as those in Rotterdam and Utrecht, respectively (Table 1). Across all sites most visitors have been observed around Groningen's market square (sites III and IV), followed at a considerable distance by Rotterdam's Stadhuisplein (site IV). Visitor numbers also varied markedly over the course of the evening (Table 2). An inverse U-shaped pattern of rise until a peak around 1:30AM (round III) followed by decline was evident in Groningen, whilst a continuous decrease took place in Rotterdam. Utrecht was positioned in-between with a slight increase until midnight (round II), followed by stabilisation and modest decrease from $\pm 2: 30 \mathrm{AM}$ (round IV) onwards. These differences suggest that the evening economy is developed rather well compared to the night and late-night economy in Rotterdam. In

\footnotetext{
${ }^{2}$ Henceforth we use this term to denote all racial/ethnic categories other than white/Caucasian.
} 
terms of visitor numbers, Groningen has a more vibrant night economy (rounds II-III) and especially late-night economy (rounds IV-V) than the other cities.

$<$ Tables 1-2 here>

The differences in racial/ethnic diversity among the three cities were bigger than among sites within them and than over the course of the evening. Whilst there are differences between Kruiskade (site III) and the other sites in Rotterdam, diversity in this city is much greater than in Groningen and Utrecht. Perhaps most surprising is that Utrecht is the least racially/ethnically mixed, despite its $22 \%$ share of inhabitants from nonWestern descent. These differences become even clearer when the average shares of non-white visitors in general, blacks and those from Arabic descent are considered. The respective shares for Rotterdam were $42 \%, 11 \%$ and $19 \%$, against $15 \%, 3 \%$ and $8 \%$ for Groningen and $11 \%, 2 \%$ and $5 \%$ in Utrecht. The whiteness of Utrecht's night-time economy primarily reflects the type of bars and clubs on offer there, which are oriented strongly towards highly educated, typically white university students and/or urban professionals (see Section 4). This interpretation is not only supported by interviews with city-council officials but also by the fact that racial/ethnic diversity is greater in site IV (Table 1), where one club explicitly targeting a diverse crowd is located. Another reason for the more diverse population in site IV is its location on a major thoroughfare from the railway station to the (north)east of the city-centre and the city, which means that more non-clubbers and bar goers have been observed there than in other sites in Utrecht. Groningen resembles Utrecht but the racial imbalance is weaker and concentrated around the market square (site III) where nightlife premises are also oriented towards a highly educated (student) public. Changes in the patterns of racial/ethnic diversity change over the course of the evening are only modest (Table 2). In Groningen a slight decrease in diversity occurs around 1:00AM, whilst the converse is true for Utrecht; Rotterdam shows little variation over time. 
Like earlier studies (Bromley et al., 2003; Roberts and Turner, 2005), we observe a general underrepresentation of women: across all observation intervals the ratio of men to women was almost 2:1 (Table 1). Rotterdam exhibited the lowest gender balance, but there was sizable heterogeneity across sites in Groningen en Utrecht. From a temporal perspective, the share of women decreased between the first and the fifth observation round but both the extent and shape of this pattern differed by city (Table 2). Only in Rotterdam did we detect the anticipated pattern of the highest share in the evening economy (round I), followed by lower shares in the night and late-night economy (rounds II-II and IV-V, respectively). The pattern in Utrecht was more irregular, and in Groningen differences across rounds were relatively small.

Variations in moving unaccompanied by all, female and non-white visitors tended to be bigger within than between Groningen, Utrecht and Rotterdam (Table 1). Nonetheless, temporal differences generally outweighed spatial differences. The most noticeable result is, however, that women were much less likely to traverse streets unaccompanied than men, particularly in Rotterdam. A roughly U-shaped relation existed between time of night and the share of unaccompanied persons across racial/ethnic and gender categories (Table 2): it was lower in the night economy (especially round III) than in the evening economy (round I) and increased substantially from round III to the end of the late-night economy. Temporal differences were, however, smaller in Rotterdam than in Groningen and Utrecht.

\section{Entrainment in nightscape dynamics}

\subsection{Regression analysis}

Beyond visitor presence, surveillance and policing practices and disorderliness also had their own rhythms in the nightlife districts of Groningen, Utrecht and Rotterdam. These 
rhythms again differed substantially between and within the cities, but our analysis does align with the temporal segmentation into an evening, night and late-night economy proposed by Bromley et al (2003) and Rowe and Bavinton (2011). Space constraints prevent us from offering detailed descriptions of all these rhythms (but see Figures A-B in the supplementary online material). Suffice it to say that police presence tended to increase from near absence in the evening economy to a peak at the end of the night economy period (round III), then to fall slightly but increase again until the end of the late-night period (round V). In contrast, the number of private security guards - mostly door staff - was coupled more strongly with those of the total number of visitors, particularly in Groningen and Utrecht. It was also evident that the number of police officers and door staff was much higher in Rotterdam than elsewhere, reflecting the city's zero-tolerance policing approach. Further, few instances of disorderliness were observed, with the exception of public drunkenness. All forms of disorder had their own rhythm and peaked in the late-night period (rounds IV and V), as did active interventions of police officers and private security guards in the practices of visitors. Overall, the atmosphere tended to be convivial and friendly across observation rounds in Utrecht and Groningen. The situation was more mixed in Rotterdam: in the verbal accounts Brands and Timan used words like 'deserted' and 'quiet' rather frequently to describe the Schouwburgplein (site I) and spoke a number of times about the aggressive atmosphere in sites III-IV in the later hours of the night.

We have conducted regression analysis to better understand the polyrhythmic ensemble of the night-time economy and to explore whether some of the rhythms described here entrain, or are at least related to, those of visitor presence. The six indicators of visitor rhythms have been regressed on a large number of potential independent variables, derived from the existing literature and our preliminary research (Section 2.2):

- Nightlife facilities around the observation site: The number of bars/clubs that were open during an observation interval, the number of snack bars, and the presence of a casino and theatre/cinema; 
- Surveillance and policing: The number of police officers and cars and private security guards, and the presence of police on foot, on horseback or in a van observed in a given interval. The wearing of stage props (Goffman, 1959), such as mobile cameras, weapons, specific clothing and communication devices, is also considered;

- Disorderliness: The presence of vandalism, public drunkenness, drug use, street refuse and panhandlers, and observed interventions by the police or private security guards;

- Smellscape: the presence of food smells and the stench of beer, urine, drug use and fumes;

- Weather: strength of wind (no/very weak/weak and medium) and precipitation (dry/drizzle/light rain/heavy rain) and the temperature in ${ }^{\circ} \mathrm{C}$;

- Time and place: indicators for day of the week, observation round, city, site, and first-order interactions of these.

For a number of these variables we also considered registrations from the previous round to account for temporally lagged pace-making effects. In all models excepting that for the total visitor number visitors' characteristics were also included.

Given the limited number of cases $(n=180)$, we have specified the regression models as parsimonious as possible: only statistically significant $(p<0.10)$ have been retained. We have used basic OLS regression modelling because more advanced model structures that can account for the spatiotemporal dependencies between the observation intervals require more cases than we have available. Results should therefore be interpreted with caution. We also emphasise the exploratory character of the analysis: whilst we have used various qualitative materials (see Section 3 ) as guidance in model specification and interpretation, regression modelling reveals the synchronisation of rhythms but not necessarily who/what is entrained or acts as pacemaker. Still, the use of those qualitative materials for interpreting the quantitative results has aided our understanding of patterns of causality. Using those qualitative materials has also allowed us to more 
comprehensively reckon with the nondeterministic nature of entrainment processes in the interpretation phase.

\subsection{Visitor number}

To facilitate the interpretation of the results for the other indicators, we begin with discussing the model for the total visitor number. Four main conclusions can be drawn. Firstly, and in line with expectations, the number of bars/clubs that are open is one of the strongest pace-makers of visitor presence: each additional bar or disco generates on average 14 extra persons observed per ten-minute observation interval. This strong pace-making effect is also evident from Jelle and Tjerk's audio-recorded narratives recorded. Secondly, the time and place indicators were coupled most strongly to visitor presence. All else equal, the southeast side of Groningen's market (site III) and to a lesser extent Poelestraat (site II) attract the most visitors, and Rotterdam in general and Stadhuisplein (site IV) in particular the fewest. The lower numbers for Stadhuisplein and the western side of Utrecht's Janskerkhof (site II) indicate that there is little beyond the presence of bars and clubs (which is controlled through the number of bars/clubs variable) that attracts persons to these sites at night-time. From a temporal perspective, the largest crowds were observed on Saturdays although visitors tended to arrive considerably later on those nights than on Thursdays and especially on Fridays: only from round III onwards were \pm 90 more visitors observed on Saturdays. The positive effect for round I in Rotterdam corroborates the earlier conclusion that Rotterdam has the strongest evening economy of the three cities.

$<$ Table 3 here $>$

Thirdly, there exist complex patterns of synchronisation between the rhythms of visitors and of surveillance and policing. The number of police officers and private security guards is positively correlated with the number of visitors, but the equipment used 
offsets these effects. The number of police cars in a given and the preceding observation round is negatively correlated to the number of visitors. The wearing of communication devices (mobile phones, walkie-talkies) by police and of black attire rather than a suit by door staff and other private security guards is also negatively associated with the number of visitors. Finally, there seemingly are no direct pace-making effects of disorderliness on visitor presence, as none of the relevant variables is included in the model. Only the rhythms of windy weather and food smells were systematically coupled to lower visitor numbers.

\subsection{Racial/ethnic diversity}

The model confirms that the degree of racial/ethnic diversity is driven more by structural factors than by rhythms on the time scale of the night or week. In fact, it is dominated by city indicators showing that racial/ethnic diversity is much larger in Rotterdam than in Groningen and Utrecht and slightly larger in Groningen than in Utrecht (Table 4). There are also place variations within each city: Kruiskade (site II), the northwest side of the Neude square (site IV), and Papengang (site I) are most mixed in racial/ethnic terms in Rotterdam, Utrecht and Groningen, respectively.

$<$ Table 4 here $>$

Three rhythmic factors are nonetheless coupled to racial/ethnic diversity in the regression analysis. Based on our observations, on interviews with non-white revellers in Utrecht and other Dutch cities and on Boogaarts's (2008) research, we are inclined to interpret the negative effect of private security guards in black clothing - all of whom were door staff - as indicating that young adults with Arabic and Surinamese/Antillean backgrounds avoid premises where door staff control entry. On the basis of the same sources, we speculate that the positive correlation between the number of police officers and racial/ethnic diversity may reflect that places with more non-white visitors are 
surveilled more intensely in light of influential popular and media discourses in the Netherlands that link youths from non-white and especially Moroccan descent to higher levels of crime and anti-social behaviour. Finally, instances of vandalism seem to act more clearly as a pace-maker deterring non-white visitors than for whites.

\subsection{Gender balance}

Rhythmic factors dominate the model in Table 5 and are more important than structural factors. The strongest pace-maker of gender-based exclusion is collective habits as approximated by the rhythm of total visitor numbers. The positive coefficient for this variable indicates that the pattern of increasing reveller numbers over the first observation rounds, followed by a peak and then decline is more pronounced for female than for male participants in the night-time economy. Hence, women participate to a greater extent in the night-time economy during the busiest hours and appear to be guided more strongly by the collective rhythm of going out than do men. These findings also indicate that, all else equal, women in Groningen, Utrecht and Rotterdam participate less in the evening and late-night economies and most in the middle period (11:30PM2:30PM). Given that opening hours of bars/clubs are important pace-makers for the total number of visitors, the results in Table 5 further imply that opening hours have stronger pace-making effects for women than for men. This conclusion is confirmed when regression models are run without indicators of visitors' characteristics.

$<$ Table 5 here $>$

After the number of visitors, the time and place indicators are coupled most tightly to the rhythms of gender balance. The two Thursday variables show that women's tendency to follow the collective rhythm is weaker on that day. This suggests that female university students, whose night out is typically the Thursday, behave differently compared to women who tend to go out on Fridays and Saturdays. The positive 
coefficients for rounds II and IV in Utrecht indicate that the concentration of women's participation in the night economy and in the first half of the late-night period is stronger in that city. There are also structural differences between sites in Utrecht and other places where observations have been conducted: women's share in the total visitor number is 11 percent-points higher at the western side of Janskerkhof (site II) and 4 percent-points at the southern side of Neude (site III). This reflects the almost exclusive orientation of nightlife facilities on university students and young urban professionals in these sites, as well as the presence of a sorority in the northeast corner of Janskerkhof.

The rhythms of surveillance and policing practices are coupled differently to those of male and female night-time economy participants. Whilst the number of private security is associated positively with gender balance, the presence of police officers in the previous round and the simultaneous presence of police in distinct clothing - typically yellowish reflecting vests - have negative effects on women's participation relative to men's in the night-time economy. The latter results throw into question the belief that more policing enhances females' inclusion in the night-time economy and suggest that the stage prop (Goffman, 1959) of distinct clothing may deter women more than men.

\subsection{Moving unaccompanied}

Several findings from the models for unaccompanied persons in general, non-whites and women (Table 6) are relevant for the discussion of rhythmic inequality and exclusion. The first is that the collective rhythms of visitor presence shape those of the shares of unaccompanied persons, non-whites and women in multiple ways. Most significant for our purposes is the result that women more often traverse the streets alone when the ratio of female to male visitors is higher. This aligns with our exploratory interviews and Sheard's (2011) qualitative study among women in Leeds showing that women feel more confident and empowered when sites within the night-time economy are less male- 
dominated. Note that the racial/ethnic composition of the transient visitor population has no effect on non-whites' inclination to move through the night-time economy unaccompanied.

$<$ Table 6 here $>$

Also of interest is that there are multiple place and time-specific variations in the rhythms of moving unaccompanied by women and non-whites. For instance, the rhythms of unaccompanied women are more pronounced than for men. Whilst men and people from different racial/ethnic backgrounds are also more likely to participate in Thursday's evening economy than in the night and late-night economy, this effect is stronger for women. For them a similar effect can also be observed on Fridays, albeit in weaker form. Women also move through the streets unaccompanied less often than men towards the end of the night on Thursdays. Regarding race/ethnicity, the models indicate that nonwhites more often move unaccompanied through large parts of Utrecht's nightlife district (with the exception of site II where all nightlife premises target students and young professionals, among whom non-whites are underrepresented), as well as Groningen's site I which houses a Dutch-style coffee shop and a non-mainstream club.

Finally, the rhythmic effects of surveillance and policing practices are again complex. The number of police officers is positively correlated with the share of unaccompanied women but negatively with that of unaccompanied non-white people. Thus, whereas more police on the streets may empower women in the night-time economy, the converse might hold for visitors from Arabic, Afro-American, Asian or Latino descent. There is also a negative effect of the rhythms of private security in black clothing - that is, door staff - on those of unaccompanied non-whites. Our qualitative material and Boogaarts's (2008) research suggests that this negative effect reflects informal rules that clubs in Utrecht and Rotterdam sometimes enact and according to which unaccompanied young males from non-white origin are refused entrance. 


\section{Conclusion and discussion}

The rhythmic analysis of nightlife in the city-centres of Groningen, Utrecht and Rotterdam in The Netherlands allows several conclusions about inequality and exclusion in the night-time economy to be drawn. For one, inequalities along lines of race/ethnicity and gender in visitor presence are substantial. Across all observation rounds and cities only one in approximately three visitors was female; the share of non-white visitors differed from two in every five visitors in Rotterdam to one in every nine in Utrecht. There are, however, important rhythmic dimensions to (potential) exclusion on the time scales of the night and week and these are stronger for gender than for race/ethnicity. In many cases these rhythms are place specific and differ between city-centres or sites within these, which aligns with Lefebvre's (2004) and others' insistence that rhythms are mediated by place and integrate space and time. The implication is that research on exclusion in the night-time economy requires us to think in terms of temporal ecologies.

With regard to gender-based inequality and exclusion, the opening hours of bars/clubs and collective habits of visitor populations can be identified as important pace-makers. For the rhythmic presence of unaccompanied women the composition of the transient visitor population at a site is a significant factor. Our expectation of women being more excluded in the night and late-night economy than in the evening economy has been confirmed only partially. The share of unaccompanied women was indeed highest in the evening economy, but the relative numbers of women and men more generally were most balanced in the night economy.

Despite its rhythmicity, the more durable dimensions of gender-based inequality and exclusion should not be overlooked. Transient visitor populations were male dominated during all observation intervals, and the regression analysis provided indications that 
gender balance may be higher in places where nightlife facilities are oriented very strongly towards highly educated crowds of students and young urban professionals (see in particular the effects for Utrecht's sites II and III). Here we encounter a dilemma: what is beneficial in gender terms can be the opposite from a racial/ethnic perspective. For our analysis also implies that the strong orientation on highly educated consumers of bars and clubs in the city-centres of Groningen and especially Utrecht is a key factor in the relative absence of non-white night-time economy participants. Thus, the role of the type of nightlife entertainment in patterns of exclusion becomes more complex than previously acknowledged when multiple axes of social differentiation are considered.

Together with a more racially diverse resident population, the more varied and segmented supply of nightlife entertainment is a critical factor in the greater participation of racial/ethnic minorities in Rotterdam's night-time economy. Our expectation that racial/ethnic inequalities would be less rhythmic than those based on gender is thus confirmed. Nonetheless, the presence of non-white visitors and their inclination to move unaccompanied through the night-time economy does have rhythmic dimensions. When the quantitative analysis is combined with our exploratory interviews, other materials collected in the context of our wider research project and the earlier work by Boogaarts (2008), the rhythms of door staff regulating access to nightlife facilities can be identified as a relevant pace-maker: their presence at certain venues at particular times seems to induce a self-imposed absence from the night-time economy among at least some non-white youth.

More generally, the patterns of synchronisation of surveillance and policing with the rhythms of all visitors, women and racial/ethnic minorities tended to be complex. The effects of greater police presence were sometimes contradictory, and we can speculate that more police officers may stimulate women's confidence to move through the nightlife district unaccompanied at night whilst simultaneously reducing non-whites' inclination to do so. Moreover, the stage props (Goffman, 1959) police and private 
security guards use may well offset the inclusion resulting from more surveillance and policing agents on the street. Our findings thus challenge the belief that more surveillance and policing are a necessary condition for attracting more visitors and a more diverse crowd in terms of gender and race/ethnicity into a city-centre's night-time economy. A final conclusion is that our quantitative analysis did not show the rhythms of disorderliness to have major impact on those of visitors in general, women and of racial/ethnic minorities.

As already explained, our analysis should be considered exploratory and partial. One strength of our approach is that it has offered numerical information on the rhythms of visitor presence and of inequalities and (potential) exclusion along lines of gender and race/ethnicity in different night-time economies, thereby complementing the qualitative approaches of earlier studies. Understanding of rhythmic conformity in night-time economies has also been deepened. Yet, a relative weakness is that less detailed insight than with qualitative methods has been obtained in the exact mechanisms through which women and certain racial/ethnic groups are excluded or defect from the night-time economy. The agency of individuals resisting the forces of entrainment and exclusion has also remained underexposed. Future research should therefore examine entrainment processes using one or more of the following methods: accompanying revellers and police officers through a nightlife district and (participant) observation with door staff; analysing time-lapse footage from CCTV and other cameras, either in real time from a CCTV control room or in more detail at a later point in time; and reflexive interviews with nightlife visitors organised on the basis of camera footage they record over the course of one or several nights out. Work along these lines should also consider more axes of social differentiation - socioeconomic status, age, sexuality, religion and subculture are the most obvious - and their intersections with each other, gender and race/ethnicity (cf McCall, 2005; Valentine, 2007), as this would offer more nuanced understanding of the inequalities and exclusions in night-time economies. 


\section{Acknowledgements}

This research is part of the project Surveillance in Urban Nightscapes, financed by the Netherlands Organization for Scientific Research (NWO), grant MVI-313-99-140. Grateful thanks to Jesse Nortier for making photographs and the three reviewers for their helpful comments.

\section{References}

Adam B, 2004 Time (Polity, Cambridge)

Amin A, Thrift N, 2002 Cities: Reimaging the Urban (Polity, Cambridge)

Boogaarts S, 2008, "Claiming your place at night: Turkish dance parties in the Netherlands" Journal of Ethnic and Migration Studies 34 1283-1300

Böse M, 2005, "Difference and exclusion at work in the club culture" International Journal of Cultural Studies 8 427-444

Bromley RDF, Tallon AR, Thomas CJ, 2003, "Disaggregating the space-time layers of city-centre activities and their users" Environment and Planning A 35 1831-1851

Chatterton P, Hollands R, 2003, Urban Nightscapes: Youth Cultures, Pleasure Spaces and Corporate Power (Routledge, London)

Crang M, 2001, "Rhythms of the city: temporalised space and motion", in TimeSpace: Geographies of Temporality eds J May, N Thrift (Routledge, London), pp 187-207

DeLanda M, 2002 Intensive Science and Virtual Philosophy (Continuum, London)

Edensor T, Holloway J, 2008, "Rhythmanalysing the coach tour: the Ring of Kerry, Ireland" Transactions of the Institute of British Geographers 33 483-501

Goffman E, 1959 The Presentation of Self in Everyday Life (Penguin Books, London)

Hadfield P (2008) "From threat to promise: nightclub 'security', governance and consumer elites" British Journal of Criminology 48 429-447

Hadfield P, Lister S, Traynor S, 2009, "'This town's a different town today': Policing and regulating the night-time economy', Criminology \& Criminal Justice 9 465-485

Hastings M H, Reddy A B, Maywood E S, 2003, "A clockwork web: circadian timing in the brain and periphery, in health and disease" Nature Reviews Neuroscience 4 649-661

Hägerstrand T, 1970, "What about people in regional science?" Regional Science Association Papers 24 7-24 
Jayne M, Holloway S L, Valentine G, 2006, "Drunk and disorderly: alcohol, urban life and public space" Progress in Human Geography 30 451-468

Jones O, 2011, "Lunar-solar rhythmpatterns: towards material cultures of tides" Environment and Planning A 43 2285-2303

Kirby S, Hewitt L, 2011, "The impact of the Licensing Act 2003 on drinking habits, offences of crime and disorder, and policing in England's newest city" Safer Communities $1031-38$

Koskela H, 1997, "'Bold walk and breakings': Women's spatial confidence versus fear of violence", Gender, Place and Culture 4 301-320

Kwan MP, Schwanen T, 2009, "Quantitative revolution 2: The critical (re)turn" The Professional Geographer 61, 283-291

Latham A, 2003, "Urbanity, lifestyle and making sense of the new urban cultural economy: notes from Auckland, New Zealand" Urban Studies 40 1699-1724

Lefebvre H, 2004 Rhythmanalysis: Space, Time and Everyday Life (Continuum, London)

McCall L, 2005, "The complexity of intersectionality" Signs 30 1771-1802

Measham F, Hadfield, P, 2009, "Everything starts with an ' $E$ ': exclusion, ethnicity and elite formation in contemporary English clubland" Adicciones 21 362-386

Pain R, 2000, "Place, social relations and the fear of crime: a review" Progress in Human Geography 24 365-387

Parkes D, Thrift N, 1979, "Time spacemakers and entrainment" Transactions of the Institute of British Geographers 4 353-372

Parkes D, Thrift N, 1980 Times, Spaces and Places: A Chronogeographic Perspective (John Wiley \& Sons, Chichester)

Roberts M, Eldridge A, 2009 Planning the Night-time City (Routledge, London)

Roberts M, Turner C, 2005, "Conflicts of liveability in the 25-hour city: learning from 48 hours in the life of London's Soho" Journal of Urban Design 10 171-193

Rowe D, Bavinton N, 2011, "Tender for the night: after-dark cultural complexities in the night-time economy" Continuum: Journal of Media \& Cultural Studies 25 811-825

Sheard L, 2011 "'Anything could have happened': women, the night-time economy, alcohol and drink spiking" Sociology 45 619-633

Sheppard E, 2001, "Quantitative geography: representations, practices, and possibilities" Environment and Planning D: Society and Space 19 535-554

Strogatz S, 2003 Sync: The Emerging Science of Spontaneous Order (Hyperion Books, New York)

Talbot D, 2007 Regulating the Night: Race, Culture and Exclusion in the Making of the Night-time Economy (Ashgate, Aldershot)

Thomas TJ, Bromley RDF, 2000 "City-centre revitalisation: problems of fragmentation and fear in the evening and night-time economy" Urban Studies 37 1403-1429 
Valentine G, 2007, "Theorizing and researching intersectionality: a challenge for feminist geography" The Professional Geographer 59 10-21

Valentine G, Holloway SL, Jayne M, 2010, "Contemporary cultures of abstinence and the nighttime economy: Muslim attitudes towards alcohol and the implications for social cohesion" Environment and Planning A 42 8-22

Van Aalst I, Schwanen T, 2009, "Omstreden nachten: angstgevoelens van jongeren in de uitgaansgebieden van Arnhem en Apeldoorn" in Omstreden Ruimte: Over de Organisatie van Spontaniteit en Veiligheid eds H Boutellier, N Boonstra, M Ham (Van Gennip, Amsterdam) pp 157-175

Whyte W H, 1980 The social life of small urban spaces (Conservation Foundation, Washington, D.C.) 


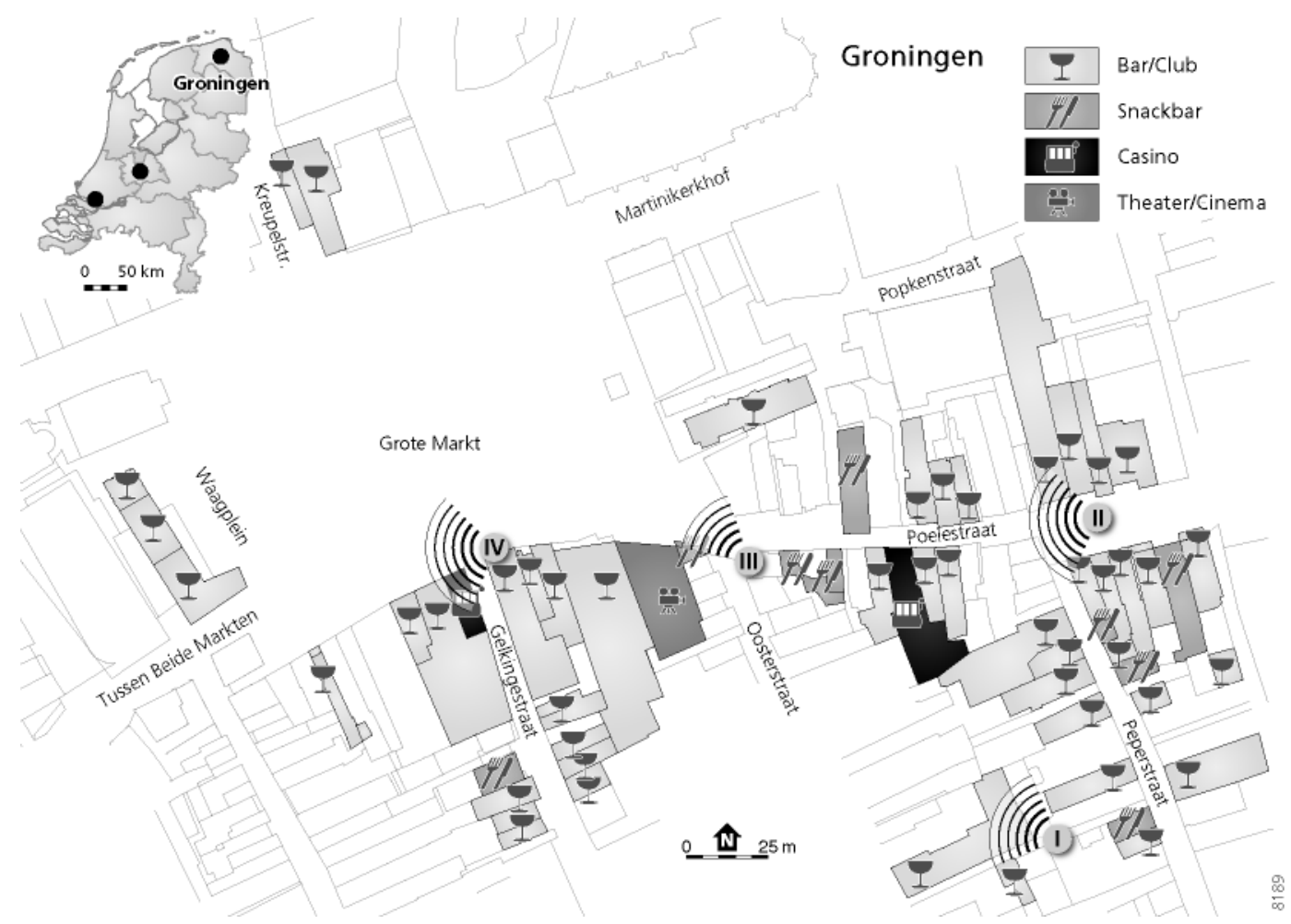

Figure 1. Nightlife district in Groningen. 

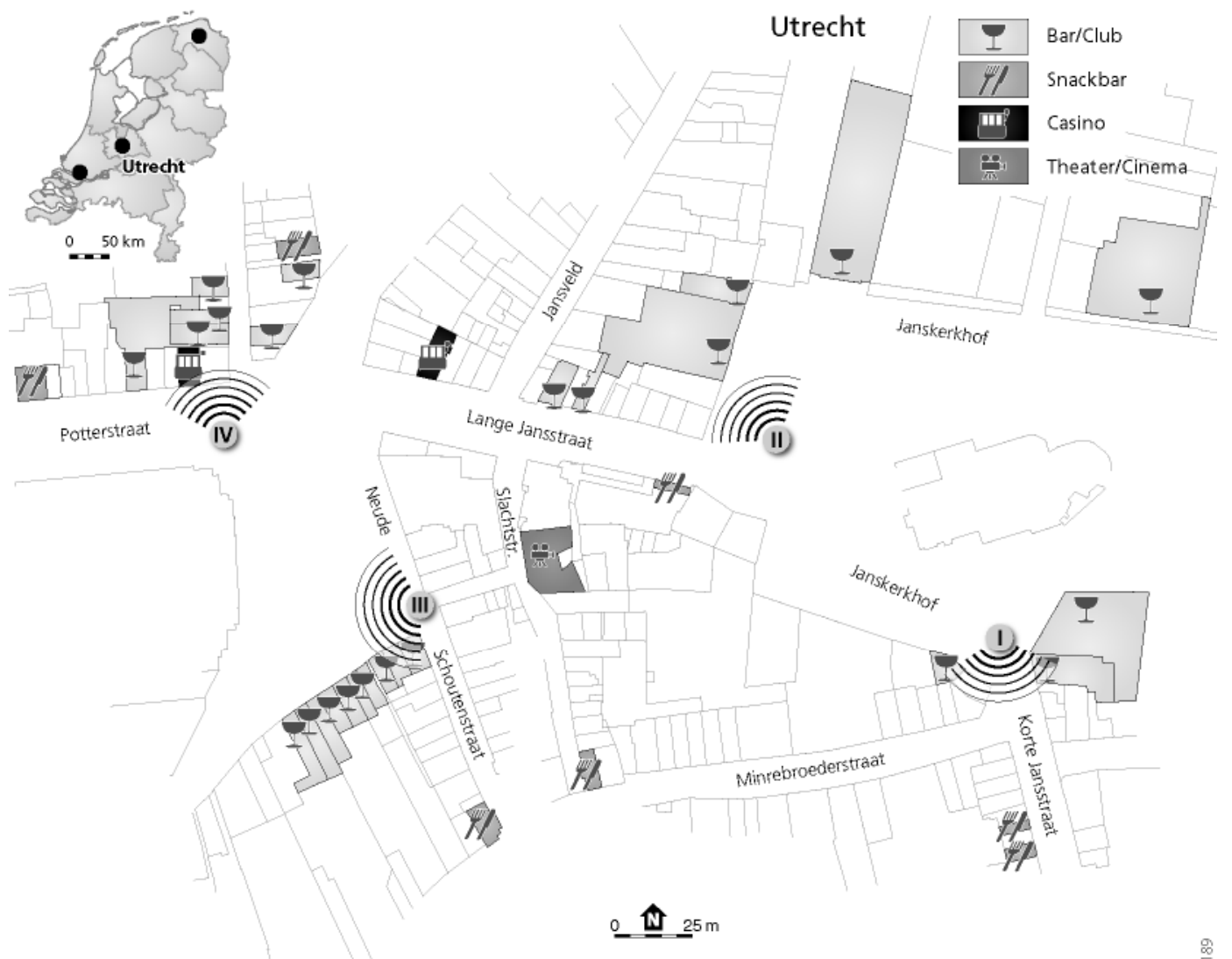

Figure 2. Nightlife district in Utrecht. 


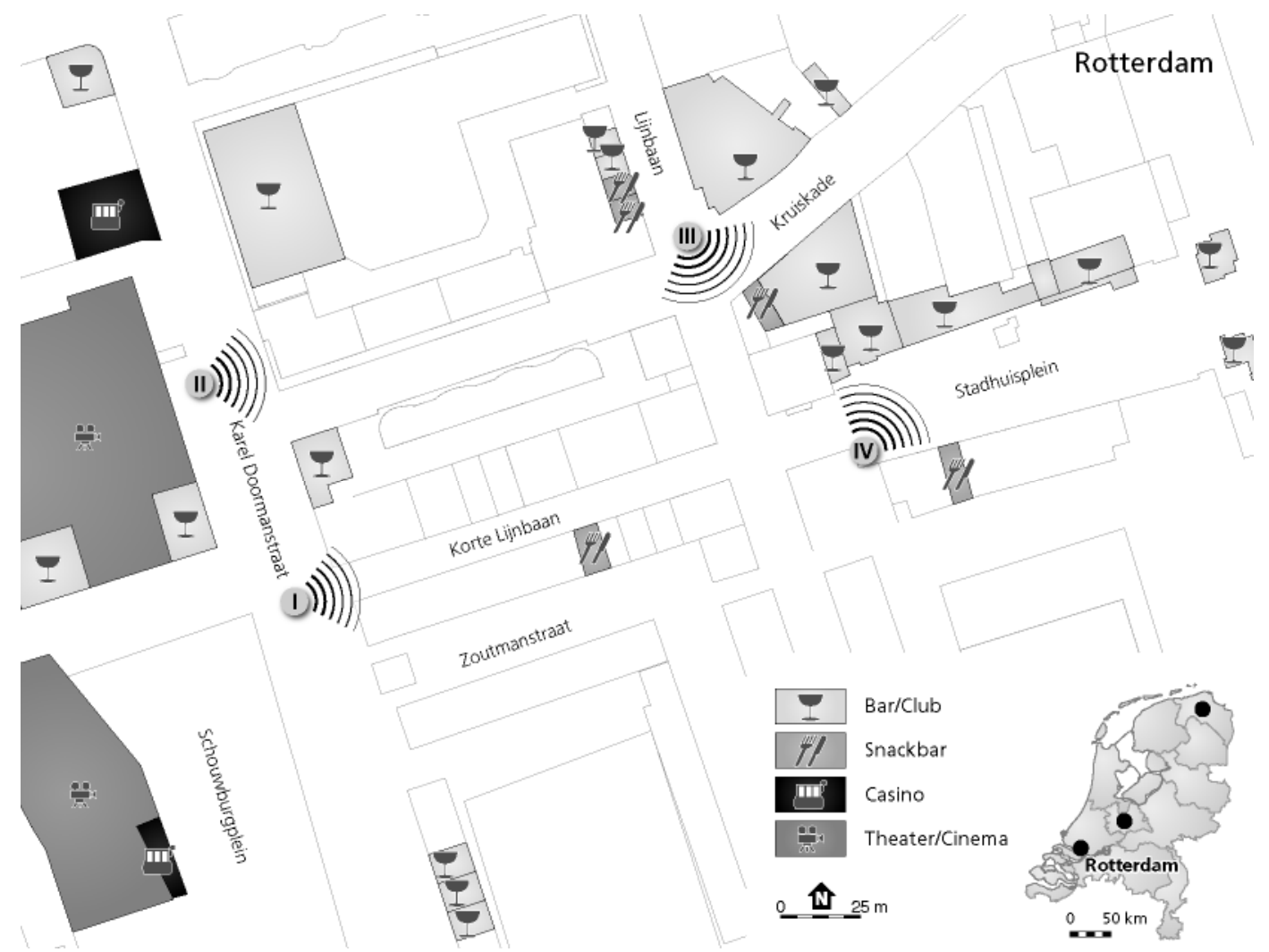

Figure 3. Nightlife district in Rotterdam. 
Table 1. Nightscape visitors per observation interval, by city and site.

\begin{tabular}{|c|c|c|c|c|c|c|c|}
\hline & & $\begin{array}{c}\text { Number of } \\
\text { people }\end{array}$ & $\begin{array}{l}\text { Share of } \\
\text { women }\end{array}$ & $\begin{array}{l}\text { Racial } \\
\text { diversity } \\
\text { index }\end{array}$ & $\begin{array}{c}\text { Share of } \\
\text { unaccompanied } \\
\text { persons }\end{array}$ & $\begin{array}{c}\text { Share of } \\
\text { unaccompanied } \\
\text { women }\end{array}$ & $\begin{array}{c}\text { Share of } \\
\text { unaccompanied } \\
\text { non-whites }\end{array}$ \\
\hline \multirow[t]{5}{*}{ Groningen } & Site I & 97 & 31.0 & 0.42 & 23.3 & 32.3 & 3.4 \\
\hline & Site II & 102 & 30.1 & 0.40 & 19.4 & 16.9 & 2.6 \\
\hline & Site III & 378 & 40.0 & 0.28 & 12.3 & 21.2 & 3.1 \\
\hline & Site IV & 381 & 38.9 & 0.28 & 14.3 & 20.3 & 3.5 \\
\hline & All & 268 & 36.6 & 0.32 & 16.4 & 22.7 & 3.4 \\
\hline \multirow[t]{5}{*}{ Utrecht } & Site I & 73 & 41.8 & 0.20 & 18.8 & 30.6 & 4.9 \\
\hline & Site II & 95 & 36.9 & 0.17 & 13.7 & 11.9 & 3.3 \\
\hline & Site III & 101 & 38.1 & 0.20 & 16.2 & 30.2 & 3.9 \\
\hline & Site IV & 98 & 32.9 & 0.38 & 19.9 & 30.5 & 3.9 \\
\hline & All & 92 & 37.4 & 0.23 & 17.2 & 25.8 & 4.0 \\
\hline \multirow[t]{5}{*}{ Rotterdam } & Site I & 84 & 30.5 & 0.61 & 19.4 & 27.4 & 2.5 \\
\hline & Site II & 116 & 33.5 & 0.59 & 16.1 & 20.3 & 2.0 \\
\hline & Site III & 125 & 31.3 & 0.69 & 16.9 & 16.5 & 1.7 \\
\hline & Site IV & 170 & 34.0 & 0.57 & 15.8 & 19.2 & 1.9 \\
\hline & All & 124 & 32.3 & 0.62 & 17.1 & 20.8 & 2.0 \\
\hline \multicolumn{2}{|c|}{ All cities and sites } & 161 & 35.4 & 0.39 & 16.9 & 23.1 & 3.1 \\
\hline
\end{tabular}


Table 2. Nightscape visitors per observation interval, by city and time of night.

\begin{tabular}{|c|c|c|c|c|c|c|c|}
\hline & & $\begin{array}{l}\text { Number of } \\
\text { people }\end{array}$ & $\begin{array}{l}\text { Share of } \\
\text { women }\end{array}$ & $\begin{array}{l}\text { Racial } \\
\text { diversity } \\
\text { index }\end{array}$ & $\begin{array}{c}\text { Share of } \\
\text { unaccompanied } \\
\text { persons }\end{array}$ & $\begin{array}{c}\text { Share of } \\
\text { unaccompanied } \\
\text { non-whites }\end{array}$ & $\begin{array}{l}\text { Share of } \\
\text { unaccompanied } \\
\text { women }\end{array}$ \\
\hline \multirow[t]{5}{*}{ Groningen } & Round I & 176 & 36.4 & 0.35 & 22.6 & 38.1 & 5.1 \\
\hline & Round II & 232 & 38.9 & 0.37 & 17.3 & 24.5 & 3.1 \\
\hline & Round III & 393 & 36.6 & 0.30 & 11.4 & 16.8 & 1.8 \\
\hline & Round IV & 333 & 36.6 & 0.30 & 13.5 & 16.9 & 3.2 \\
\hline & Round V & 207 & 34.2 & 0.27 & 17.3 & 17.1 & 3.7 \\
\hline \multirow[t]{5}{*}{ Utrecht } & Round I & 95 & 38.0 & 0.21 & 20.8 & 28.1 & 5.8 \\
\hline & Round II & 106 & 42.7 & 0.20 & 14.7 & 23.2 & 3.0 \\
\hline & Round III & 104 & 35.0 & 0.26 & 10.7 & 20.1 & 2.3 \\
\hline & Round IV & 92 & 39.9 & 0.25 & 20.0 & 24.7 & 5.5 \\
\hline & Round V & 62 & 31.4 & 0.26 & 19.7 & 32.8 & 3.5 \\
\hline \multirow[t]{5}{*}{ Rotterdam } & Round I & 168 & 40.8 & 0.58 & 16.8 & 19.5 & 2.9 \\
\hline & Round II & 157 & 35.4 & 0.65 & 16.6 & 21.4 & 3.0 \\
\hline & Round III & 124 & 29.2 & 0.63 & 17.5 & 19.7 & 0.9 \\
\hline & Round IV & 94 & 27.4 & 0.63 & 16.0 & 18.1 & 1.2 \\
\hline & Round V & 78 & 28.5 & 0.59 & 18.5 & 26.0 & 2.0 \\
\hline \multirow[t]{5}{*}{ All cities } & Round I & 146 & 38.4 & 0.38 & 20.0 & 28.6 & 4.6 \\
\hline & Round II & 165 & 39.0 & 0.41 & 16.2 & 23.0 & 3.0 \\
\hline & Round III & 207 & 33.6 & 0.39 & 13.2 & 18.9 & 1.7 \\
\hline & Round IV & 173 & 34.7 & 0.39 & 16.5 & 19.9 & 3.3 \\
\hline & Round V & 116 & 31.5 & 0.37 & 18.5 & 25.3 & 3.1 \\
\hline
\end{tabular}


Table 3. Regression model for total number of people observed.

\begin{tabular}{|c|c|c|c|}
\hline & B & Beta & Sig \\
\hline Constant & 93.8 & & 0.000 \\
\hline $\begin{array}{l}\text { Nightlife premises } \\
\text { Number of bars/clubs open }\end{array}$ & 14.3 & 0.27 & 0.000 \\
\hline $\begin{array}{l}\text { Surveillance and policing } \\
\text { Number of police officers } \\
\text { Number of police cars } \\
\text { Number of police cars in previous round } \\
\text { Police wear communication devices (yes }=1 \text { ) } \\
\text { Number of private security } \\
\text { Number of private security in previous round } \\
\text { Private security in black clothing (yes }=1 \text { ) }\end{array}$ & $\begin{array}{r}15.8 \\
-48.8 \\
-43.0 \\
-35.4 \\
6.2 \\
10.1 \\
-23.8\end{array}$ & $\begin{array}{r}0.15 \\
-0.22 \\
-0.16 \\
-0.07 \\
0.14 \\
0.21 \\
-0.09\end{array}$ & $\begin{array}{l}0.011 \\
0.000 \\
0.000 \\
0.077 \\
0.067 \\
0.001 \\
0.049\end{array}$ \\
\hline $\begin{array}{l}\text { Smellscape } \\
\text { Smell of food (yes }=1 \text { ) }\end{array}$ & -57.9 & -0.15 & 0.001 \\
\hline $\begin{array}{l}\text { Weather } \\
\text { Wind }\end{array}$ & -23.0 & -0.16 & 0.000 \\
\hline $\begin{array}{l}\text { Time and place } \\
\text { Thursday*Round I } \\
\text { Saturday } \\
\text { Saturday }{ }^{\star} \text { Round I } \\
\text { Saturday*Round II } \\
\text { Groningen, Site II } \\
\text { Groningen, Site III } \\
\text { Utrecht, Site II } \\
\text { Rotterdam } \\
\text { Rotterdam*Round I } \\
\text { Rotterdam, Site II } \\
\text { Rotterdam, Site IV }\end{array}$ & $\begin{array}{r}-76.3 \\
92.2 \\
-125.7 \\
-46.1 \\
165.9 \\
311.2 \\
-69.4 \\
-78.0 \\
115.8 \\
82.0 \\
-73.5\end{array}$ & $\begin{array}{r}-0.14 \\
0.32 \\
-0.23 \\
-0.08 \\
0.32 \\
0.59 \\
-0.14 \\
-0.27 \\
0.22 \\
0.17 \\
-0.15\end{array}$ & $\begin{array}{l}0.001 \\
0.000 \\
0.000 \\
0.061 \\
0.000 \\
0.000 \\
0.001 \\
0.000 \\
0.000 \\
0.000 \\
0.004\end{array}$ \\
\hline Adjusted $R^{2}$ & & 0.776 & \\
\hline
\end{tabular}


Table 4. Regression model for racial/ethnic diversity.

\begin{tabular}{lrrr}
\hline & B & Beta & Sig. \\
\hline Constant & 0.27 & & 0.000 \\
Surveillance and policing & & & \\
Number of police officers & 0.02 & 0.109 & 0.006 \\
Private security in black clothing (yes=1) & -0.04 & -0.093 & 0.019 \\
Disorderliness & & & \\
Vandalism (yes=1) & -0.09 & -0.074 & 0.053 \\
Time and place & & & \\
Groningen, Site I & 0.17 & 0.230 & 0.000 \\
Utrecht & -0.08 & -0.186 & 0.000 \\
Utrecht, Site IV & 0.17 & 0.230 & 0.000 \\
Rotterdam & 0.32 & 0.745 & 0.000 \\
Rotterdam, Site III & 0.11 & 0.151 & 0.000 \\
Adjusted $R^{2}$ & & 0.753 & \\
\hline
\end{tabular}


Table 5. Regression model for share of women.

\begin{tabular}{lrrr}
\hline & B & Beta & Sig. \\
\hline Constant & 1.60 & & 0.615 \\
Visitors' characteristics & & & \\
Number of visitors (Natural log) & 6.77 & 0.641 & 0.000 \\
Surveillance and policing & & & \\
Police in distinct clothing (yes=1) & -4.19 & -0.181 & 0.003 \\
Number of police officers in previous round & & & \\
Police on foot in previous round (yes=1) & -4.56 & -0.138 & 0.028 \\
Number of private security & 0.39 & 0.118 & 0.076 \\
Time and place & & & \\
Thursday*Round I & 5.89 & 0.150 & 0.010 \\
Thursday*Round V & 4.23 & 0.104 & 0.082 \\
Saturday*Round V & -3.88 & -0.099 & 0.085 \\
Utrecht, Site II & 10.93 & 0.309 & 0.000 \\
Utrecht, Site III & 4.24 & 0.120 & 0.046 \\
Utrecht*Round II & 6.04 & 0.154 & 0.010 \\
Utrecht*Round IV & 4.59 & 0.117 & 0.051 \\
Adjusted $R^{2}$ & & 0.480 & \\
\hline
\end{tabular}


Table 6. Regression models for share of unaccompanied persons, non-whites and women.

\begin{tabular}{|c|c|c|c|c|c|c|c|c|c|}
\hline & \multicolumn{3}{|c|}{ Unaccompanied persons } & \multicolumn{3}{|c|}{ Unaccompanied non-whites } & \multicolumn{3}{|c|}{ Unaccompanied women } \\
\hline & B & Beta & Sig. & $B$ & Beta & Sig. & B & Beta & Sig. \\
\hline Constant & 41.26 & & 0.000 & 0.401 & & 0.000 & 4.604 & & 0.004 \\
\hline $\begin{array}{l}\text { Visitors' characteristics } \\
\text { Number of visitors (natural log) } \\
\text { Racial diversity index } \\
\text { Share of women } \\
\text { Share of women (natural log) }\end{array}$ & $\begin{array}{r}-4.65 \\
5.97 \\
-0.18\end{array}$ & $\begin{array}{r}-0.476 \\
0.135 \\
-0.197\end{array}$ & $\begin{array}{l}0.000 \\
0.029 \\
0.003\end{array}$ & -0.035 & -0.186 & 0.012 & -1.108 & -0.338 & 0.001 \\
\hline $\begin{array}{l}\text { Surveillance and policing } \\
\text { Number of police officers } \\
\text { Number of police cars in previous round } \\
\text { Police using mobile cameras (yes }=1 \text { ) } \\
\text { Private security in black clothing (yes }=1 \text { ) }\end{array}$ & $\begin{array}{r}2.46 \\
-6.78\end{array}$ & $\begin{array}{r}0.137 \\
-0.159\end{array}$ & $\begin{array}{l}0.015 \\
0.007\end{array}$ & $\begin{array}{l}-0.017 \\
-0.040\end{array}$ & $\begin{array}{l}-0.126 \\
-0.113\end{array}$ & $\begin{array}{l}0.085 \\
0.099\end{array}$ & 0.362 & 0.156 & 0.023 \\
\hline $\begin{array}{l}\text { Disorderliness } \\
\text { Vandalism (yes }=1 \text { ) } \\
\text { Homeless person(s) (yes=1) }\end{array}$ & 3.62 & 0.146 & 0.010 & -0.119 & -0.113 & 0.116 & & & \\
\hline $\begin{array}{l}\text { Weather } \\
\text { Wind } \\
\text { Temperature }\end{array}$ & 0.92 & 0.096 & 0.088 & & & & -0.265 & -0.299 & 0.000 \\
\hline $\begin{array}{l}\text { Time and place } \\
\text { Thursday*Round I } \\
\text { Thursday*Round III } \\
\text { Thursday*Round V } \\
\text { Friday }{ }^{\star} \text { Round I } \\
\text { Friday*Round II }\end{array}$ & 7.65 & 0.217 & 0.000 & $\begin{array}{l}0.082 \\
0.104\end{array}$ & $\begin{array}{l}0.118 \\
0.144\end{array}$ & $\begin{array}{l}0.091 \\
0.044\end{array}$ & $\begin{array}{r}4.373 \\
-2.572 \\
-1.670 \\
2.321 \\
2.258\end{array}$ & $\begin{array}{l}0.801 \\
-0.213 \\
-0.133 \\
0.193 \\
0.187\end{array}$ & $\begin{array}{l}0.000 \\
0.002 \\
0.056 \\
0.004 \\
0.004\end{array}$ \\
\hline $\begin{array}{l}\text { Groningen, Site I } \\
\text { Groningen, Site II } \\
\text { Groningen, Site III }\end{array}$ & & & & 0.085 & 0.135 & 0.062 & $\begin{array}{l}1.914 \\
1.983\end{array}$ & $\begin{array}{l}0.165 \\
0.182\end{array}$ & $\begin{array}{l}0.023 \\
0.012\end{array}$ \\
\hline $\begin{array}{l}\text { Utrecht } \\
\text { Utrecht, Site II }\end{array}$ & & & & $\begin{array}{r}0.084 \\
-0.191\end{array}$ & $\begin{array}{r}0.227 \\
-0.303\end{array}$ & $\begin{array}{l}0.004 \\
0.000\end{array}$ & & & \\
\hline $\begin{array}{l}\text { Utrecht*Round III } \\
\text { Utrecht*Round IV } \\
\text { RotterdamRound IV }\end{array}$ & $\begin{array}{l}-7.30 \\
-5.34\end{array}$ & $\begin{array}{l}-0.207 \\
-0.151\end{array}$ & $\begin{array}{l}0.000 \\
0.012\end{array}$ & & & & 1.848 & 0.153 & 0.026 \\
\hline Adjusted $R^{2}$ & & 0.508 & & & 0.212 & & & 0.290 & \\
\hline
\end{tabular}


